\title{
- POZIOM POCZUCIA WŁASNEJ SKUTECZNOŚCI KOBIET CIĘŻARNYCH A WYBRANE ASPEKTY PRZEBIEGU PORODU
}

\section{THE EFFICIENCY AWARENESS LEVEL OF PREGNANT WOMEN AND SELECTED ASPECTS OF THE COURSE OF CHILDBIRTH}

\author{
Dorota Rogala ${ }^{1}$, Roman Ossowski ${ }^{2,3}$ \\ Katedra Onkologii, Radioterapii i Ginekologii Onkologicznej \\ Uniwersytet Mikołaja Kopernika w Toruniu, Collegium Medicum im. Ludwika Rydygiera w Bydgoszczy \\ ${ }^{2}$ Zakład Psychologii Rehabilitacyjnej \\ Uniwersytet Mikołaja Kopernika w Toruniu, Collegium Medicum im. Ludwika Rydygiera Bydgoszczy \\ ${ }^{3}$ Katedra Społecznej Psychologii Zdrowia, Rehabilitacji i Zarządzania, Instytut Psychologii \\ Uniwersytet Kazimierza Wielkiego w Bydgoszczy
}

DOI: https://doi.org/10.20883/pielpol.2017.60

\section{STRESZCZENIE}

Cel. Celem badań była ocena związku między poziomem poczucia własnej skuteczności a wybranymi aspektami przebiegu porodu.

Materiał i metody. Badaniami objęto 234 kobiety w 38.-42. tygodniu ciąży o prawidłowym przebiegu, które zostały podzielone na dwie grupy: I - 96 kobiet z niskim i średnim poczuciem skuteczności, i II - 138 kobiet z wysokim poczuciem skuteczności. Wśród wskaźników przebiegu porodu analizowano: czas trwania porodu, poziom aktywności własnej podczas porodu, korzystanie ze środków przeciwbólowych, stan noworodka, sposób ukończenia porodu i subiektywną ocenę porodu. Wykorzystano ankietę własnej konstrukcji, Skalę Uogólnionej Własnej Skuteczności GSES i dokumentację szpitalną. W ocenie uogólnionej własnej skuteczności posłużono się skalą stenową do opisu poziomu skuteczności badanych kobiet.

Wyniki. Kobiety z ciążą o prawidłowym przebiegu mają wysoki poziom uogólnionej skuteczności - 30,19 - w stosunku do średniej polskiej - 27,32. Nie wykryto zależności między poziomem własnej skuteczności a czasem trwania porodu, aktywnością rodzącej, ilością zastosowanych środków przeciwbólowych, sposobem ukończenia porodu. Kobiety, które urodziły dzieci w lepszym stanie, oceniły wysoko swoje kompetencje i były zadowolone z opieki personelu, miały wyższe poczucie własnej skuteczności. Wnioski. Przebieg porodu prawdopodobnie bardziej zależy od właściwości biofizycznych kobiety, a poczucie własnej skuteczności odgrywa w nim rolę stymulującą, a nie determinującą.

SŁOWA KLUCZOWE: Skala Uogólnionej Własnej Skuteczności, kobieta ciężarna, poród.

\section{Wprowadzenie}

Pojęcie własnej skuteczności to pojęcie oznaczające poziom szacunku do siebie i własnych kompetencji w zmaganiach się z wyzwaniami życiowymi. Problem ten podjął w ujęciu systemowym Albert Bandura, twór-

\section{ABSTRACT}

Aim. The research was mainly aimed at the assessment of the relation between the efficiency awareness level of pregnant women and selected aspects of the course of childbirth.

Material and methods. The study involved 234 women at 38 -42 weeks of the gestation with the proper course who were divided into two groups: I - 96 women with a low and medium sense of self-efficacy and II - 138 women with a high sense of self-efficacy. The following were analysed amongst the indicators of the course of childbirth: childbirth duration time, own activity level during childbirth, application of painkillers, newborn child's condition, parturition method and subjective evaluation of childbirth. The research was performed using the personal survey, the General Self-Efficacy Scale - GSES questionnaire and data collected from the documentation of the hospital record. In general self-efficacy evaluation, the standard ten scale was used to describe the efficacy level of the women involved in research.

Results. Women with a normal course of pregnancy characterized by high levels of generalized efficiency - 30.19 - compared to the average Polish - 27.32. The childbirth duration time, own activity level, application of painkillers, parturition method did not differ between women with different levels of the GSES. Women who gave birth in a better condition, found high competence and were satisfied with the staff care, had higher self-efficacy.

Conclusions. The course of delivery is probably more dependent on the biophysical properties of women, and self-efficacy plays a stimulating, not determining role.

KEYWORDS: General Self-Efficacy Scale, pregnant women, childbirth.

ca społeczno-poznawczej teorii uczenia się nowych zachowań i ich podtrzymywania [1, 2]. Zgodnie z teorią Bandury zaangażowanie człowieka w różne zachowania zależy od jego przekonania, czy spodziewana zmiana zachowania jest wartościowa (oczekiwanie skutku), 
czy określone zachowanie pozwoli osiągnąć zamierzony cel (oczekiwanie wyniku) i czy dana jednostka ma wystarczające kompetencje do wykonania danego zadania (oczekiwanie dotyczące własnej skuteczności). Tego rodzaju przekonania nie muszą jednak pochodzić tylko z osobistych doświadczeń, lecz być także następstwem obserwacji zachowań innych osób. Ważne są obserwacje zachowań ludzi w różnych sytuacjach. Przekonanie, że jest się wystarczająco kompetentnym, motywuje jednostkę do podejmowania i podtrzymywania określonej aktywności. Koncepcja Bandury jest więc podejściem behawiorystycznym w sensie uczenia się przez doświadczanie skutecznych następstw własnych zachowań; ma także charakter poznawczy w sensie uczenia się przez obserwację zachowań innych osób. Warto zachowywać się podobnie jak inne osoby, jeśli prowadzi to do uzyskania wyniku. Autor w procesie uczenia się docenia znaczenie społecznych interakcji, czyli uczymy się w otoczeniu innych osób, obserwując następstwa ich zachowań. Mogą być one modelami dla danej uczącej się osoby.

Nie ma w podejściu Bandury bezpośredniego związku między bodźcem a reakcją. Zmienną pośredniczącą, czy moderatorem zmian w zachowaniu, są procesy poznawcze wyrażające się w interpretacji zachowań własnych i innych osób. Zachowania innych dają siłę osobie do przygotowania i realizacji dostępnych zasobów własnych celem zrealizowania konkretnych planów działania. Ma to szczególne znaczenie w sytuacjach nowych, nie do końca przewidywalnych. Bandura przeprowadził wiele badań nad poczuciem własnej skuteczności, przez którą rozumiał poczucie szacunku do siebie i własnej kompetencji w zmaganiach z życiowymi wyzwaniami. Zdaniem Bandury ludzie o znacznym poczuciu własnej skuteczności wierzą w zdolność radzenia sobie z rozmaitymi zdarzeniami życiowymi. Ludzie o niskim poczuciu własnej skuteczności odczuwają bezradność, a nawet beznadziejność, zwłaszcza w sytuacjach trudnych.

Teoria społeczno-poznawcza Bandury stała się inspiracją dla badań w psychologii zdrowia [3-6]. Rozpoczęcie działania - jak podaje Juczyński - wymaga odpowiedniej siły, zaś jego podtrzymanie musi być wspierane wytrwałością. Poczucie własnej skuteczności określa wielkość zainwestowanego wysiłku i stopień wytrwałości w dążeniu do zamierzonego celu. Jest zatem czynnikiem motywacyjnym w zapoczątkowaniu działania i przebiegu procesu radzenia sobie w nieoczekiwanych sytuacjach [4].

Poczucie skuteczności różnicuje ludzi pod względem odzwierciedlania życiowych wyzwań i zamiarów co do sposobu działania. Im silniejsze są przekonania danej jednostki co do własnej skuteczności, tym wyższe stawia sobie ona cele, wytrwalej do nich dąży nawet w obliczu piętrzących się trudności i tym silniej angażuje się w zamierzenia mimo porażek. Niskie z kolei poczucie skuteczności wiąże się z depresją, lękiem i bezradnością oraz niechęcią do przejawiania zamiarów działania [4, 7-9]. Ci, którzy wysoko oceniają swoją skuteczność, są pewni siebie, chętniej podejmują się realizacji zadań, są wytrwali w działaniach. Ci zaś, którzy nie wierzą w swoje siły, nawet jeśli podejmą się wyzwania, szybko się zniechęcają, gdy wystąpią trudności. Wysoka samoskuteczność sprzyja pozytywnym zachowaniom zdrowotnym [10-12] i jest predykatorem trwałych zmian w walce z nałogiem [13, 14].

Spostrzegana skuteczność sprzyja również lepszemu radzeniu sobie ze stresem, lepszej kontroli bólu, wpływa mobilizująco na funkcje układu immunologicznego. Funkcje układu krążenia w chorobie wieńcowej szybciej stabilizują się u tych pacjentów, którzy wierzą, że to od nich samych zależy, czy poradzą sobie z chorobą $[8,9,15,16]$. Osoby po udarze mózgu lepiej oceniają swoją jakość życia [17]. U osób z nowotworem wysoka skuteczność sprzyja wyborowi aktywnych strategii do walki z chorobą [18-20].

\section{Cel pracy}

W okresie ciąży w organizmie każdej kobiety oprócz zmian natury biologicznej zachodzi szereg zmian psychologicznych, które wymagają od kobiety szczególnych form przystosowania. W przebiegu całej ciąży, a w szczególności w okresie porodu, kobiety narażone są na ogromny stres psychologiczny. Głównymi czynnikami wpływającymi na nasilenie stresu są zarówno sam przebieg ciąży i porodu, jak i zmienne indywidualne, takie jak struktura osobowości, zakres wiedzy dotyczący ciąży, porodu i jego przebiegu, preferowane style radzenia sobie ze stresem związanym z ciążą i porodem oraz wsparcie uzyskiwane od otoczenia. Szczególnie ważne jest wsparcie od personelu medycznego i najbliższej rodziny. Stres psychologiczny może wpływać niekorzystnie na sam przebieg ciąży, a reakcje osi nerwowo-immunologiczno-dokrewnej mogą zaburzać przebieg porodu [21]. Organizm człowieka jest wyposażony w mechanizmy homeostazy i jeśli czynnik zagrażający jest krótkotrwały, to jest w stanie utrzymać równowagę. W przypadku percepcji bodźca jako długotrwale oddziałującego lub silnie zagrażającego równowaga ta może zostać zachwiana [22]. Wysoki poziom poczucia własnej skuteczności zgodnie z koncepcją Bandury może okazać się pomocny w zmaganiu się ze stresującymi przeżyciami związanymi z przebiegiem porodu [1, 2].

Dostępne badania poczucia własnej skuteczności wśród kobiet w okresie ciąży dotyczyły ciężarnych 
z ciążą wysokiego ryzyka [9]. Nie badano dotychczas grupy kobiet rodzących z niskim ryzykiem powikłań. Interesujące więc wydaje się podjęcie próby przeanalizowania, czy istnieje jakaś zależność między poziomem poczucia własnej skuteczności rodzących kobiet a różnymi elementami przebiegu porodu w jego kolejnych fazach.

Główna hipoteza brzmi: istnieje współzależność między poczuciem własnej skuteczności a korzystnym przebiegiem porodu. Warunkiem brzegowym doboru próby do badań była pozytywna prognoza medyczna co do przebiegu porodu i nieprzewidywanie powikłań.

\section{Materiał i metody}

Badaniami na wstępie objęto 300 kobiet w 38.-42. tygodniu ciąży o prawidłowym przebiegu, które urodziły żywy płód w oddziałach położniczych Wielospecjalistycznego Szpitala Miejskiego im. dr. Emila Warmińskiego w Bydgoszczy. Ze względu na fakt, że 64 kobiety odmówiły uczestnictwa w badaniu bądź też zrezygnowały w trakcie jego trwania, ostatecznie analizą objęto 234 kobiety. Badania przeprowadzono wśród położnic w 2.-3. dobie po porodzie.

Wiek badanych kobiet mieścił się w przedziale 17 -46 lat $(M=28,9 ; S D=5,1)$. Wśród 234 kobiet najwięcej kobiet miało wykształcenie wyższe - $50 \%$, najmniej podstawowe/gimnazjalne - 5\%; wykształcenie zawodowe $-10 \%$, średnie/pomaturalne - 35\%. Kobiet stanu wolnego było $23 \%$, mężatek - 77\%. Większość kobiet zamieszkiwała w miastach - 79\%, na wsiach mieszkało $21 \%$. Połowa kobiet była pierwszy raz w ciąży, dla połowy była to ciąża kolejna. W badanej grupie przeważały kobiety rodzące po raz pierwszy - 58\%. Wieloródki stanowiły $42 \%$ kobiet. Regularnie na zajęcia do szkoły rodzenia uczęszczały 84 kobiety - 36\%. Ogólnie można stwierdzić, że rodzące kobiety przejawiały wysoką świadomość zdrowotną.

W badaniu wykorzystano: kwestionariusz ankiety dostarczający informacji o danych demograficznych i uczęszczaniu do szkoły rodzenia, standaryzowane narzędzie - Skalę Uogólnionej Własnej Skuteczności (Generalized Self-Efficacy Scale - GSES) Schwarzera i Jerusalema z Freie Universität Berlin, opracowaną w 1992 roku, a zaadoptowaną w Polsce we współpracy z Juczyńskim w 1998 roku, oraz dokumentację szpitalną. $\mathrm{Na}$ zastosowanie wyżej wymienionych narzędzi uzyskano zgodę Komisji Bioetycznej przy Collegium Medicum UMK w Toruniu.

Wśród wskaźników przebiegu porodu analizowano: czas trwania porodu, poziom aktywności własnej podczas porodu (korzystanie z drabinek, materacy, worka sako, immersji), korzystanie ze środków przeciwbó- lowych (Dolcontral, znieczulenie zewnątrzoponowe ZOP), stan noworodka (wg skali Apgar i ph z pępowiny), sposób ukończenia porodu (poród fizjologiczny, kleszcze, cięcie cesarskie ze wskazań nagłych i elektywne) oraz subiektywną ocenę porodu (przeżycia związane z porodem, samoocena kobiety rodzącej, wyobrażenie o porodzie, opieka personelu).

Badana próba została podzielona na grupy pod względem prezentowanego poziomu własnej skuteczności mierzonego w jednostkach standaryzowanych (stenach) za pomocą GSES. Skala składa się z 10 stwierdzeń, z możliwością udzielenia odpowiedzi ocenianych w granicach od 1 do 4 punktów. Suma wszystkich punktów daje ogólny wskaźnik poczucia własnej skuteczności w zakresie od 10 do 40 punktów. Im wyższy wynik, tym większe poczucie własnej skuteczności. Ogólny wskaźnik po przekształceniu na jednostki standaryzowane podlega interpretacji stosownie do właściwości charakteryzujących skalę stenową. Wyniki w granicach 1-4 stena (10-24 punkty) przyjęto traktować jako wyniki niskie, zaś w granicach 7-10 stena (30-40 punkty) jako wysokie, co odpowiada obszarowi ok. 33\% wyników najniższych i tyle samo najwyższych w skali. Wyniki w granicach 5 i 6 stena (25-29 punktów) traktuje się jako przeciętne. Skala charakteryzuje się wysokim współczynnikiem $\alpha$ Cronbacha - 0,85 [9].

W obliczeniach statystycznych zastosowano z-test w oparciu o rozkład normalny i nieparametryczny test niezależności chi-kwadrat. Przy $p<0,05$ różnica uznawana była za statystycznie istotną (is), w przeciwnych przypadkach - za nieistotną (ns).

\section{Wyniki}

Pierwsze pytanie badawcze ma charakter pytania dopełnienia i dotyczy rozkładu badanej próby pod względem uogólnionej własnej skuteczności mierzonej GSES.

Tabela 1. Rozkład badanej próby pod względem poziomu uogólnionej własnej skuteczności mierzonej GSES ( $n=234)$

Table 1. Distribution of the sample in terms of the level of the generalized self-efficacy measurement GSES $(n=234)$

\begin{tabular}{ccccccccccc}
\hline $\begin{array}{c}\text { Poziom GSES/The level of self- } \\
\text { efficacy }\end{array}$ & \multicolumn{4}{c}{ Niski/Low } & $\begin{array}{c}\text { Średni/ } \\
\text { Medium }\end{array}$ & Wysoki/High \\
\hline Sten/Sten & 1 & 2 & 3 & 4 & 5 & 6 & 7 & 8 & 9 & 10 \\
llość kobiet/The number of women & 0 & 0 & 0 & 8 & 39 & 49 & 85 & 39 & 7 & 7 \\
Razem/Total & & $\mathrm{n}=8$ & & $\mathrm{n}=88$ & & $\mathrm{n}=138$ & \\
\hline
\end{tabular}

Jednostki sten odpowiadające niskiemu (10-24 pkt), średniemu (2529 pkt) i wysokiemu (30-40 pkt) poczuciu skuteczności/Sten unit corresponding to a low (10-24 pts), average (25-29 pts) and high (30-40 pts) sense of efficacy

Źródło: badania własne

Source: author's own materials 
Z tabeli wynika, że najwięcej kobiet $(n=138)$ cechowało się wysokim, a najmniej $(n=8)$ - niskim poziomem własnej skuteczności. Ze względu na zbyt małą liczebnie grupę kobiet z niskim poczuciem własnej skuteczności zdecydowano się na połączenie w jedną grupę kobiet z niskim i średnim poziomem GSES. Uzyskano w ten sposób dwie podgrupy poddawane dalszej analizie. Pierwszą stanowiły kobiety z niskim i średnim poczuciem własnej skuteczności ( $n=96)$, drugą - kobiety z wysokim poczuciem własnej skuteczności $(n=138)$. Średni wynik GSES dla wszystkich badanych kobiet wyniósł 30,19.

Kolejne pytania mają charakter pytań rozstrzygnięć. Pierwsze dotyczą współzależności między poziomem własnej skuteczności a wskaźnikami przebiegu porodu. Statystyczne opracowanie zależności między poziomem własnej skuteczności kobiet ciężarnych a wybranymi wskaźnikami przebiegu porodu przedstawiają poniższe tabele.

Tabela 2. Czas trwania porodu w zależności od poziomu poczucia własnej skuteczności ( $n=161$ - tylko poród naturalny i kleszczowy)

Table 2. The duration of labor, depending on the level of self-efficacy ( $n=161$ - only normal vaginal delivery and forceps delivery)

\begin{tabular}{|c|c|c|c|c|c|}
\hline & & \multicolumn{2}{|c|}{$\begin{array}{c}\text { Poziom GSES/The level of self- } \\
\text { efficacy }\end{array}$} & \multirow{2}{*}{ Z } & \multirow{2}{*}{$p$} \\
\hline & & $\begin{array}{l}\text { niski i średni/ } \\
\text { low and medium }\end{array}$ & wysoki/high & & \\
\hline \multirow{3}{*}{ I } & $n$ & 62 & 99 & \multirow{3}{*}{1,03} & \multirow{3}{*}{0,30} \\
\hline & M & 268,7 & 295,0 & & \\
\hline & SD & 139,2 & 183,5 & & \\
\hline \multirow{3}{*}{$\|$} & $\mathrm{n}$ & 62 & 99 & \multirow{3}{*}{0,63} & \multirow{3}{*}{0,53} \\
\hline & M & 18,5 & 21,2 & & \\
\hline & SD & 25,2 & 28,6 & & \\
\hline \multirow{3}{*}{ III } & $n$ & 62 & 97 & \multirow{3}{*}{0,71} & \multirow{3}{*}{0,48} \\
\hline & $\mathrm{M}$ & 7,34 & 8,14 & & \\
\hline & SD & 6,15 & 7,90 & & \\
\hline
\end{tabular}

I, II, III - okres porodu; M - średnia; SD - odchylenie standardowe; $n$ - liczebność badanej grupy $\mathrm{z}$ odpowiednim poziomem GSES; z - z-test w oparciu o rozkład normalny; $p$ - poziom istotności statystycznej/I, II, III - period of labour; M - mean; SD - standard deviation; $n$-sample size with the appropriate level of GSES; $z$ - $z$-test based on a normal distribution; $p$ - level of statistical significance

Źródło: badania własne

Source: author's own materials

Test nie wykrył różnicy między średnimi czasu trwania porodu w porównywanych grupach z różnym poziomem GSES, wartości obliczonych z-statystyk są mniejsze od wartości krytycznej 1,96, p > 0,05 (ns).

Następnie badano aktywność własną pacjentek podczas porodu w zależności od poziomu poczucia własnej skuteczności. Aktywność własna rodzącej rozumiana była jako zmiana pozycji przy porodzie, np. klękanie, kucanie, chodzenie, korzystanie ze sprzętów, np. drabinek, materacy, worka sako, piłki, korzystanie z immersji, np. wanny, prysznica w czasie porodu - odpowiedź „tak” - lub niekorzystanie z żadnej formy - odpowiedź „nie”. Ze względu na brak możliwości określenia aktywności rodzącej przy cięciu cesarskim wcześniej zaplanowanym rozpatrywane były tylko przypadki porodu naturalnego, za pomocą kleszczy i cięcia cesarskiego ze wskazań nagłych - razem 196 kobiet.

Tabela 3. Aktywność własna kobiety rodzącej w zależności od poziomu poczucia własnej skuteczności ( $n=196$ - tylko poród naturalny, kleszczowy, c.c. ze wskazań nagłych)

Table 3. Laboring woman's activity, depending on the level of selfefficacy ( $n=196$ - only normal vaginal delivery, forceps, emergency cesarean section)

\begin{tabular}{cccc}
\hline \multirow{2}{*}{ Poziom GSES/The level of self-efficacy } & \multicolumn{2}{c}{ Aktywność/Activity } & Razem/ \\
\cline { 2 - 3 } & tak/yes & nie/no & Total \\
\hline Niski i średni/Low and medium & $\mathrm{n}=51$ & $\mathrm{n}=26$ & $\mathrm{n}=77$ \\
Wysoki/High & $\mathrm{n}=89$ & $\mathrm{n}=30$ & $\mathrm{n}=119$ \\
Razem/Total & $\mathrm{n}=140$ & $\mathrm{n}=56$ & $\mathrm{n}=196$ \\
\hline
\end{tabular}

$\mathrm{n}$ - liczebność badanej grupy z odpowiednim poziomem GSES/ $n$ - sample size with the appropriate level of the GSES

Źródło: badania własne

Source: author's own materials

Prawie dwie trzecie badanych kobiet były aktywne w czasie porodu. Badania wskazują jednak na brak zależności między aktywnością własną rodzących w porównywanych grupach z różnym poziomem własnej skuteczności: $\chi^{2}=1,68<3,84=\chi_{\mathrm{kr}}^{2}, \mathrm{p}=0,19$ (ns).

Kolejne pytanie dotyczyło zależności między stosowaniem środków przeciwbólowych w czasie porodu a poziomem poczucia własnej skuteczności. Środki przeciwbólowe stosowane w czasie porodu to Dolcontral i ZOP. Ze względu na brak potrzeby stosowania śródporodowo środków przeciwbólowych przy cięciu cesarskim wcześniej zaplanowanym rozpatrywane były tylko przypadki porodu naturalnego, za pomocą kleszczy i cięcia cesarskiego ze wskazań nagłych - razem 196 kobiet.

Tabela 4. Stosowanie środków przeciwbólowych w zależności od poziomu poczucia własnej skuteczności ( $n=196$ - tylko poród naturalny, kleszczowy, c.c. ze wskazań nagłych)

Table 4. The use of painkillers, depending on the level of self-efficacy ( $n=196$ - only normal vaginal delivery, forceps, emergency cesarean section)

\begin{tabular}{cccc}
\hline & \multicolumn{3}{c}{$\begin{array}{c}\text { Stosowanie } \\
\text { środków przeciw- }\end{array}$} \\
Poziom GSES/The level of self-efficacy & $\begin{array}{c}\text { sólowych/The use } \\
\text { bazem/ } \\
\text { of painkillers }\end{array}$ & Total \\
\cline { 2 - 3 } & tak/yes & nie/no & \\
\hline Niski i średni/Low and medium & $\mathrm{n}=41$ & $\mathrm{n}=37$ & $\mathrm{n}=78$ \\
Wysoki/High & $\mathrm{n}=65$ & $\mathrm{n}=53$ & $\mathrm{n}=118$ \\
Razem/Total & $\mathrm{n}=106$ & $\mathrm{n}=90$ & $\mathrm{n}=196$ \\
\hline
\end{tabular}

n - liczebność badanej grupy z odpowiednim poziomem GSES/ $n$ - sample size with the appropriate level of the GSES

Źródło: badania własne

Source: author's own materials 
Ponad połowa kobiet korzystała ze środków przeciwbólowych, ale nie wykryto zależności między poziomem poczucia własnej skuteczności a częstotliwością ich stosowania: $\chi^{2}=0,26<3,84=\chi_{\mathrm{kr}}^{2}, \mathrm{p}=0,61$ (ns).

Następnie analizowano zależności między poziomem własnej skuteczności a stanem noworodka. Wzięto pod uwagę ocenę jego stanu za pomocą pomiaru ph z pępowiny i punktacji w skali Apgar. Pomiar za pomocą ph jest jedyną obiektywną formą oceny stanu narodzonego dziecka opierającą się na badaniu krwi pępowinowej. Ocena za pomocą skali Apgar, stosowana rutynowo po porodzie, dotyczy subiektywnej oceny stanu noworodka przez personel, więc obarczona jest większym prawdopodobieństwem błędu.

Tabela 5. Wynik pH z pępowiny w zależności od poziomu poczucia własnej skuteczności $(n=234)$

Table 5. The $\mathrm{pH}$ of the umbilical cord, depending on the level of selfefficacy $(n=234)$

\begin{tabular}{|c|c|c|c|c|}
\hline \multirow[b]{2}{*}{$\mathrm{pH}$} & \multicolumn{2}{|c|}{$\begin{array}{l}\text { Poziom GSES/The } \\
\text { level of self-efficacy }\end{array}$} & \multirow[b]{2}{*}{$z$} & \multirow[b]{2}{*}{$p$} \\
\hline & $\begin{array}{c}\text { niski } \\
\text { i średni/ } \\
\text { low and } \\
\text { medium }\end{array}$ & $\begin{array}{l}\text { wysoki/ } \\
\text { high }\end{array}$ & & \\
\hline $\mathrm{n}$ & 96 & 138 & & \\
\hline$M$ & 7,32 & 7,34 & 1,98 & $<0,05$ \\
\hline SD & 0,08 & 0,07 & & \\
\hline
\end{tabular}

$\mathrm{pH}$ - badanie gazometryczne wykonywane bezpośrednio po pobraniu próbki krwi z tętnicy pępowinowej; wartość $\mathrm{pH}<7,0$ jest uznawana za wykładnik istotnej kwasicy noworodka; M - średnia; SD - odchylenie standardowe; $n$ - liczebność badanej grupy z odpowiednim poziomem GSES; z-z-test w oparciu o rozkład normalny; p - poziom istotności statystycznej/ $\mathrm{pH}$ - gasometry study performed immediately after sampling blood from the umbilical cord; $\mathrm{pH}<7.0$ is considered an important exponent of the acidosis newborn; $M$ - mean; $S D$ - standard deviation; $n$ - the sample size with the appropriate level of the GSES; $z-z$-test based on a normal distribution; $p$-level of statistical significance

Źródło: badania własne

Source: author's own materials

Badania pokazały, że średni poziom pH był wyższy w grupie kobiet z wysokim poziomem własnej skuteczności $(p<0,05)$.

Tabela 6. Punktacja Apgar w zależności od poziomu poczucia własnej skuteczności ( $\mathrm{n}=131$ - tylko noworodki > 6 pkt)

Table 6. Apgar score depending on the level of self-efficacy $(n=131$ only infants $>6$ pts)

\begin{tabular}{ccccccc}
\hline & \multicolumn{5}{c}{ Punkty Apgar/Apgar score } & \\
\cline { 2 - 6 } Poziom GSES/The level of & $6 \mathrm{pkt}$ & $7 \mathrm{pkt}$ & $8 \mathrm{pkt}$ & $9 \mathrm{pkt}$ & $10 \mathrm{pkt}$ & $\mathrm{p}$ \\
self-efficacy & $6 \mathrm{pts}$ & $7 \mathrm{pts}$ & $8 \mathrm{pts}$ & $9 \mathrm{pts}$ & $10 \mathrm{pts}$ & \\
\hline Niski i średni/Low and medium & $\mathrm{n}=3$ & $\mathrm{n}=4$ & $\mathrm{n}=10$ & $\mathrm{n}=34$ & $\mathrm{n}=44$ & \\
Wysoki/High & $\mathrm{n}=3$ & $\mathrm{n}=6$ & $\mathrm{n}=11$ & $\mathrm{n}=47$ & $\mathrm{n}=69$ & 0,94 \\
\hline
\end{tabular}

Punkty Apgar - punktacja noworodka po urodzeniu określająca parametry czynności serca, czynności oddechowej, napięcia mięśniowego, zabarwienia skóry i reakcji noworodka na wprowadzenie cewnika do nosa (< 4 pkt - stan ciężki, 4-7 pkt - średni, 8-10 pkt - dobry); $\mathrm{n}$ - liczebność badanej grupy z odpowiednim poziomem GSES; $\mathrm{p}$ - poziom istotności statystycznej/Apgar points - neonate's score defining the parameters of the cardiac function, respiratory function, muscle tone, skin color and response of the newborn to the introduction of a catheter into the nose (< 4pts - state heavy, 4-7 pkt - average, 8-10 pkt - good); $n$ - sample size with the appropriate level of the GSES; $p$ - level of statistical significance

Źródło: badania własne

Source: author's own materials

Nie zaobserwowano zależności między punktacją Apgar noworodków w porównywanych grupach kobiet z różnym poziomem własnej skuteczności: $\chi^{2}=0,81<$ $9,49=\chi_{k r}^{2}, k=4, p=0,94(n s)$.

W kolejnym etapie analizowano sposób ukończenia porodu w zależności od poziomu poczucia własnej skuteczności.

Tabela 7. Sposób ukończenia porodu w zależności od poziomu poczucia własnej skuteczności ( $\mathrm{n}=234)$

Table 7. Mode of delivery, depending on the level of self-efficacy $(n=234)$

\begin{tabular}{|c|c|c|c|c|c|}
\hline \multirow[b]{2}{*}{$\begin{array}{l}\text { Poziom GSES/ } \\
\text { The level of self- } \\
\text { efficacy }\end{array}$} & \multicolumn{4}{|c|}{ Sposób ukończenia porodu/Mode of delivery } & \multirow[b]{2}{*}{$p$} \\
\hline & $\begin{array}{c}\text { naturalny/ } \\
\text { natural }\end{array}$ & $\begin{array}{l}\text { kleszcze/ } \\
\text { forceps }\end{array}$ & $\begin{array}{l}\text { c.c.planowe/ } \\
\text { planned } \\
\text { caesarean } \\
\text { section }\end{array}$ & $\begin{array}{c}\text { c.c.nagłe/ } \\
\text { emergency } \\
\text { cesarean } \\
\text { section }\end{array}$ & \\
\hline $\begin{array}{c}\text { Niski i średni/Low and } \\
\text { medium }\end{array}$ & $n=57$ & $n=5$ & $\mathrm{n}=19$ & $n=15$ & 0,62 \\
\hline Wysoki/High & $n=90$ & $n=9$ & $n=19$ & $n=20$ & \\
\hline
\end{tabular}

Sposób ukończenia porodu - poród drogą pochwową siłami natury (naturalny), poród drogą pochwową za pomocą kleszczy (kleszcze), c.c. - cięcie cesarskie wcześniej zaplanowane (c.c. planowe) lub ze wskazań nagłych (c.c. nagłe); $n$ - liczebność badanej grupy z odpowiednim poziomem GSES; $p$ - poziom istotności statystycznej/ Mode of delivery - vaginal natural birth, vaginal delivery using forceps, c.s. - cesarean section previously planned (c.s. planned) or emergency indications (c.s. sudden); $n$ - sample size with the appropriate level of the GSES; $p$ - level of statistical significance

Źródło: badania własne

Source: author's own materials

Najwięcej kobiet rodziło drogami natury $(n=147)$, najmniej - za pomocą kleszczy $(n=14)$. Nie zaobserwowano zależności między sposobem ukończenia porodu w porównywanych grupach kobiet $z$ różnym poziomem własnej skuteczności: $\chi^{2}=1,78<7,81=\chi_{\mathrm{kr}}^{2}, \mathrm{k}=3, \mathrm{p}=$ $0,62(n s)$.

Korzystając z obserwacji uczestniczącej, rejestrowano wypowiedzi rodzących kobiet odnośnie przeżyć związanych z porodem. 
Tabela 8. Ocena przeżyć porodu w zależności od poziomu poczucia własnej skuteczności $(\mathrm{n}=234)$

Table 8. Evaluation of live birth, depending on the level of self-efficacy $(n=234)$

\begin{tabular}{|c|c|c|c|c|}
\hline \multirow[b]{2}{*}{$\begin{array}{l}\text { Poziom GSES/ } \\
\text { The level of self- } \\
\text {-efficacy }\end{array}$} & \multicolumn{3}{|c|}{$\begin{array}{l}\text { Poród był przede wszystkim/Childbirth was } \\
\text { primarily }\end{array}$} & \\
\hline & $\begin{array}{cc} & \text { czymś, } \\
\text { pięknym } & \text { przez co } \\
\text { przeży- } & \text { musiałam } \\
\text { ciem/ przejśćl } \\
\text { a wonderful something } \\
\text { experience I had to go } \\
\text { through }\end{array}$ & $\begin{array}{l}\text { trudnym } \\
\text { przeży- } \\
\text { ciem, ale } \\
\text { nagro- } \\
\text { dzonym } \\
\text { urodzeniem } \\
\text { dziecka/ } \\
\text { a difficult } \\
\text { experience, } \\
\text { but awar- } \\
\text { ded with } \\
\text { a newborn }\end{array}$ & $\begin{array}{l}\text { koszma- } \\
\text { rem, } \\
\text { o którym } \\
\text { chciała- } \\
\text { bym zapo- } \\
\text { mniećl } \\
\text { nightmare } \\
\text { which I } \\
\text { would like } \\
\text { to forget }\end{array}$ & $p$ \\
\hline $\begin{array}{l}\text { Niski i średni/Low and } \\
\text { medium }\end{array}$ & $\mathrm{n}=10$ & $\mathrm{n}=69$ & $\mathrm{n}=5$ & 0,78 \\
\hline Wysoki/High & $n=21$ & $n=98$ & $n=4$ & \\
\hline
\end{tabular}

$\mathrm{n}$ - liczebność badanej grupy z odpowiednim poziomem GSES; $\mathrm{p}$ - poziom istotności statystycznej/ $n$ - sample size with the appropriate level of the GSES; $p$ - level of statistical significance

Źródło: badania własne

Source: author's own materials

Większość kobiet, bez względu na poziom własnej skuteczności, oceniła poród jako trudne przeżycie, ale nagrodzone urodzeniem dziecka; najmniej - jako koszmar, o którym chciałyby zapomnieć. Nie były to jednak różnice istotne statystycznie: $\chi^{2}=1,10<7,81=\chi_{\mathrm{kr}}^{2}$, $\mathrm{k}=3, \mathrm{p}=0,78$ (ns).

Kobiety w czasie porodu wypowiadały się również na temat tego, jak oceniają siebie w aspekcie wyzwania, jakie stawiał przed nimi poród.

Tabela 9. Samoocena kobiety rodzącej w zależności od poziomu poczucia własnej skuteczności ( $\mathrm{n}=196$ - tylko poród naturalny, kleszczowy, c.c. ze wskazań nagłych)

Table 9. Self-laboring woman, depending on the level of self-efficacy ( $n$ = 196 - only normal vaginal delivery, forceps, emergency cesarean section)

\begin{tabular}{|c|c|c|c|}
\hline \multirow{2}{*}{$\begin{array}{l}\text { Poziom GSES/ } \\
\text { The level of self-efficacy }\end{array}$} & \multicolumn{2}{|c|}{$\begin{array}{c}\text { Zadowolenie } \\
\text { z siebie/Smugness }\end{array}$} & \multirow{2}{*}{ Razem } \\
\hline & tak/yes & nie/no & \\
\hline $\begin{array}{l}\text { Niski i średni/ } \\
\text { Low and medium }\end{array}$ & $\mathrm{n}=60$ & $\mathrm{n}=17$ & $\mathrm{n}=77$ \\
\hline Wysoki/High & $n=107$ & $n=12$ & $\mathrm{n}=119$ \\
\hline Razem/Total & $n=167$ & $n=29$ & $n=196$ \\
\hline
\end{tabular}

$\mathrm{n}$ - liczebność badanej grupy z odpowiednim poziomem GSES/ $n$-sample size with the appropriate level of the GSES

Źródło: badania własne

Source: author's own materials
Badania pokazały, że wyższy poziom sprzyja wyższej samoocenie: $u=2,29>1,96=u_{k r}, p=0,02$ (is).

Każda kobieta będąca w ciąży czerpie wiedzę na temat porodu z różnorodnych źródeł, m.in. od personelu w czasie wizyt kontrolnych, z książek, od znajomych, a obecnie również z Internetu. Każda więc, przychodząc do szpitala, ma jakąś wizję tego, jak będzie „wyglądał” poród. Może powstać tu rozbieżność między zastaną rzeczywistością a wyobrażeniami o porodzie, co może być źródłem frustracji, niepokoju i zawiedzionych nadziei. Dane o tym, jak kobiety wyobrażały sobie poród, pochodzą z wywiadu z pacjentką po porodzie.

Tabela 10. Wyobrażenia porodu w zależności od poziomu poczucia własnej skuteczności $(\mathrm{n}=234)$

Table 10. Imaginations of birth, depending on the level of self-efficacy $(n=234)$

\begin{tabular}{|c|c|c|c|c|c|}
\hline \multirow[b]{2}{*}{$\begin{array}{c}\text { Poziom GSES/ } \\
\text { The level of self- } \\
\text { efficacy }\end{array}$} & \multicolumn{4}{|c|}{$\begin{array}{l}\text { Czy tak właśnie wyobrażała Pani sobie po- } \\
\text { ród?/Is that what you imagined childbirth? }\end{array}$} & \multirow{2}{*}{ Razem/ } \\
\hline & $\begin{array}{c}\text { Zdecydo- } \\
\text { wanie tak/ } \\
\text { Definitely } \\
\text { yes }\end{array}$ & $\begin{array}{c}\text { Raczej } \\
\text { tak/Rather } \\
\text { yes }\end{array}$ & $\begin{array}{l}\text { Raczej nie/ } \\
\text { Rather no }\end{array}$ & $\begin{array}{l}\text { Zdecydo- } \\
\text { wanie nie/ } \\
\text { Definitely } \\
\text { no }\end{array}$ & \\
\hline $\begin{array}{l}\text { Niski i średni/ } \\
\text { Low and medium }\end{array}$ & $n=4$ & $n=39$ & $n=43$ & $n=10$ & $n=96$ \\
\hline Wysoki/High & $n=13$ & $n=60$ & $n=47$ & $n=18$ & $n=138$ \\
\hline Razem/Total & $\mathrm{n}=17$ & $n=99$ & $n=90$ & $n=28$ & $\mathrm{n}=234$ \\
\hline
\end{tabular}

$\mathrm{n}$ - liczebność badanej grupy z odpowiednim poziomem GSES/ $n$-sample size with the appropriate level of the GSES

Źródło: badania własne

Source: author's own materials

Badania pokazały, że często wyobrażenia kobiet na temat porodu odbiegały od rzeczywistości. Nie wykryto natomiast zależności korelacyjnej między poziomem własnej skuteczności a wyobrażeniem porodu: $\chi^{2}=4,28$ $<7,81=\chi_{\mathrm{kr}}^{2}, \mathrm{k}=3, \mathrm{p}=0,23(n s)$.

Ostatni etap badań polegał na dokonaniu przez pacjentkę subiektywnej oceny członków zespołu terapeutycznego. Każda kobieta korzystała z punktacji od 1 do 5, oceniając w ten sposób lekarzy położników, lekarzy pediatrów, położne i pielęgniarki noworodkowe. Następnie obliczono średnie z poszczególnych ocen w każdej grupie i zastosowano z-test w celu ich porównania. Wyniki obliczeń i testowania podano niżej. 
Tabela 11. Ocena za opiekę w zależności od poziomu poczucia własnej skuteczności $(\mathrm{n}=234)$

Table 11. Assessment of the care depending on the level of selfefficacy $(n=234)$

\begin{tabular}{ccccc}
\hline & \multicolumn{3}{c}{$\begin{array}{c}\text { Poziom GSES/The } \\
\text { level of self-efficacy }\end{array}$} \\
\cline { 2 - 3 } Ocena za opiekę/Evaluation for care & $\begin{array}{c}\text { niski } \\
\text { i średni// }\end{array}$ & wysoki/ & $p$ \\
low and & high & \\
medium & & & \\
\hline n & 96 & 138 & \\
M & 4,46 & 4,64 & $<0,02$ \\
SD & 0,62 & 0,47 & \\
\hline
\end{tabular}

M-średnia; SD - odchylenie standardowe; $n$ - liczebność badanej grupy z odpowiednim poziomem GSES; $p$ - poziom istotności statystycznej/ $M$ - mean; $S D$ - standard deviation; $n$ - sample size with the appropriate level of the GSES; $p$ - level of statistical significance

Źródło: badania własne

Source: author's own materials

Test wykazał istotną różnicę - średnia ocena za opiekę jest większa w grupie z wysokim poziomem własnej skuteczności: $z=2,40>1,96=z_{k r}, p<0,02$ (is).

\section{Dyskusja}

Z przeprowadzonych badań wynika, że poziom własnej skuteczności nie różnicuje kobiet pod względem czasu trwania porodu, aktywności własnej przy porodzie, ilości zastosowanych środków przeciwbólowych, zakończenia porodu oraz oceny porodu (Tabele 2-4, 7, 8, 10). Kobiety, które urodziły dzieci w lepszym stanie, oceniły wysoko swoje kompetencje i były zadowolone z opieki personelu, miały wyższe poczucie własnej skuteczności (Tabele 5, 9, 11).

Celem oceny uzyskanych wyników poziomu własnej skuteczności usiłowano porównać je do innych przeprowadzonych badań. Dostępne są badania poziomu GSES u chorych ze stomią jelitową [23], chorobą niedokrwienną serca [24], u chorych na schizofrenię [25] i stwardnienie rozsiane [26], chorych z rozpoznaniem nowotworu narządów rodnych i wewnętrznych [27], pacjentów dializowanych, diabetyków, po zawale mięśnia sercowego [9]. Wśród kobiet najwyższy z dostępnych danych wskaźnik poczucia własnej skuteczności miały pacjentki po mastektomii $(30,07)$ i z rozpoznaniem migreny $(28,57)$, zaś najniższy - kobiety leczone z powodu objawów menopauzy $(26,12)$; dla ciężarnych z ciążą powikłaną wynosi on 26,90 . Średni wynik dla całej polskiej populacji wynosi 27,32 , a dla zdrowych kobiet - 27,13 [9]. W przeprowadzonym badaniu kobiet w ciąży o prawidłowym przebiegu poziom GSES wyniósł 30,19. Jest to więc najwyższy wskaźnik z wszystkich badanych grup klinicznych, wyższy od średniej populacji o 2,87.
W przeprowadzonym badaniu uzyskano mały odsetek wyników mówiących o niskim poczuciu skuteczności kobiet - 3\%; z drugiej strony uzyskano ponad połowę wyników odpowiadających wysokiemu poczuciu skuteczności - 59\%. Z dotychczas badanych grup klinicznych najniższy procent niskich wskaźników GSES stanowiły kobiety po mastektomii (13\%) i one również stanowiły najwyższy procent wskaźników wysokich (67\%) [28]. Wyniki przeprowadzonych badań własnych wskazują więc na ogólnie wysoką ocenę własnych możliwości przez kobiety rodzące.

Dostępność wielu metod we współczesnym położnictwie ma sprzyjać osiągnięciu ostatecznego celu: urodzeniu zdrowego dziecka. W świetle badań wysokie poczucie skuteczności sprzyja silnemu zaangażowaniu, wytrwałości, otwartości na działania, dobremu radzeniu sobie ze stresem i bólem [4, 7-9, 15, 16]. Zaangażowanie rodzącej, jej aktywność, czyli przyjmowanie dowolnych pozycji przy porodzie, korzystanie ze sprzętów, immersji wodnej, sprzyja skróceniu czasu trwania porodu, lepszemu dotlenieniu płodu, ukończeniu porodu drogami natury [29-37]. W przeprowadzonym badaniu własnym brak jest różnic między kobietami z różnym poziomem własnej skuteczności w zakresie aktywności własnej, czasu trwania porodu i zakończenia porodu. Może jest to związane z medycznymi przeciwwskazaniami, które to uniemożliwiły tym kobietom aktywność, a czynnik ten nie był uwzględniony w analizie danych. Może też, jak wskazuje Zakrzewski, samo poczucie własnej skuteczności nie wystarcza, gdy brak jest odpowiednich zdolności i umiejętności [38]. Wykazano natomiast istotnie wyższy średni poziom ph z krwi pępowinowej dzieci u kobiet $z$ wysokim GSES ( $p<0,05$ ). Również mimo braku istotnych statystycznie różnic dzieci urodzonych w dobrym stanie (8-10 pkt Apgar) było więcej wśród kobiet z wysokim GSES. Badania Schwarzer i Fuchs dowodzą również, że spostrzegana skuteczność sprzyja lepszej kontroli bólu [8]. Na podobną zależność wskazują Pietrzyk i Lizińczyk u pacjentów otrzymujących paliatywną chemioterapię [16]. Nie znalazło to potwierdzenia w przeprowadzonych badaniach, gdyż częstotliwość korzystania ze środków przeciwbólowych w obu grupach była taka sama ( $p=0,61, n s)$.

Pewną pomocą w interpretacji tego zdarzenia może być artykuł Szymony, w którym wskazuje, że poród nie tyle przebiega na poziomie struktur poznawczych, ile raczej na poziomie popędowo-emocjonalnym [21]. Wiele wyjaśniają mechanizmy biologiczne, stąd też najprawdopodobniej zależności między poziomem własnej skuteczności a przebiegiem porodu okazały się mało istotne. W sytuacjach takich jak poród poczucie własnej skuteczności odgrywa rolę stymulującą, a nie determinującą. 
Przekonanie o wysokiej własnej skuteczności wiąże się także z wysoką samooceną, samoakceptacją oraz nastawieniem optymistycznym [9]. Znalazło to odzwierciedlenie w wynikach dotyczących samozadowolenia $(p=0,02)$ i wyższych ocenach za opiekę personelu $(p<0,02)$.

Ponieważ niektóre z badań wskazują na możliwość podnoszenia lub wzmacniania poczucia własnej skuteczności przez zastosowanie odpowiednich technik poznawczo-behawioralnych, w ramach edukacji przedporodowej powinno się z technik tych korzystać, aby pomóc kobietom uwierzyć w siebie [2, 13, 39, 40]. Ma to duże znaczenie, zważywszy, że jak pokazują badania, niskie poczucie skuteczności wiąże się z depresją, lękiem i bezradnością, co może niekorzystnie rzutować na przebieg ciąży i porodu oraz dostrzegany coraz częściej problem zaburzeń depresyjnych u kobiet w połogu [4, 7-9].

Jak podaje Życińska, największe znaczenie dla kształtowania wyobrażenia o własnej skuteczności mają poprzednie doświadczenia [28]. Najważniejsze więc, aby kobieta z doświadczenia porodu wyniosła przede wszystkim zadowolenie i wysoką samoocenę, co da jej wiarę, że pokona trudności, które czekają ją na drodze macierzyństwa.

\section{Piśmiennictwo}

1. Bandura A. Self-efficacy. Toward a unifying theory of behavioral change. Psychol Rev. 1977; 84: 191-215.

2. Bandura A. Self-efficacy. The exercise of control. New York: Frejman; 1994.

3. Jarosiewicz H. Poród jako problem życiowy. W: Jędrzejczyk M, Dolińska-Zygmunt G (red.). Problemy życiowe, sytuacje trudne, zaburzenia rozwoju osobowości. Wrocław: Wyd. Uniwersytetu Wrocławskiego; 1992. 17-43.

4. Juczyński Z. Poczucie własnej skuteczności jako wyznacznik zachowań zdrowotnych. Promocja Zdrowia. Nauki Społeczne i Medycyna. 1998; 14: 54-63.

5. Juczyński Z. Przekonania i oczekiwania wyznacznikami zachowań związanych ze zdrowiem. W: Juczyński J, OgińskaBulik N (red.). Zasoby osobiste i społeczne sprzyjające zdrowiu jednostki. Łódź: Wyd. Uniwersytetu Łódzkiego; 2003. 49-61.

6. Ziarko M. Zmaganie się ze stresem choroby przewlekłej. Poznań: Wyd. Nauk. Wydziału Nauk Społecznych UAM; 2014.

7. Locke EA, Latham GP. A theory of goal setting and task performance. New York: Prentice Hall; 1990.

8. Schwarzer R, Fuchs R. Self-efficacy and health behaviours. W: Conner M, Norman P (red.). Predicting health behavior. Buckingham-Philadelphia: Open University Press; 1996. 163-196.

9. Juczyński Z. Narzędzia pomiaru w promocji i psychologii zdrowia. Warszawa: Pracownia Testów Psychologicznych PTP; 2001.

10. Żuralska R, Mziray M, Muczyn A et al. Ocena związku między zachowaniami zdrowotnymi a poczuciem własnej skuteczności u pensjonariuszy Domu Pomocy Społecznej w Gdańsku. Probl Piel. 2012; 20, 2: 247-251.
11. Baumgart M, Szpinda M, Radzimińska A et al. Poczucie własnej skuteczności a zachowania zdrowotne. J Educ Health Sport. 2015; 5, 8: 226-235.

12. Grześkowiak B, Siwy-Hudowska A. Temperament, poczucie własnej skuteczności i jakość życia kobiet regularnie uprawiających sport w porównaniu z kobietami nieaktywnymi fizycznie. J Educ Health Sport. 2016; 6, 6: 359-374.

13. Di Clemente CC, Doyle SR, Donovan D. Predicting treatment seekers' readiness to change their drinking behavior in the COMBINE Study. Alcohol Clin Exp Res. 2009; 33, 5: 879-892.

14. Laudet AB, Stanick V. Predictors of motivation for abstinence at the end of outpatient substance abuse treatment. J Subst Abuse Treat. 2010; 38, 4: 317-327.

15. Ogińska-Bulik N, Juczyński Z. Osobowość: stres a zdrowie. Warszawa: Difin; 2010.

16. Pietrzyk A, Lizińczyk S. Nadzieja podstawowa pacjentów znawrotem choroby nowotworowejorazich własnaskuteczność kontroli bólu i radzenia sobie z nim. Psychoonkologia. 2015; 1 : $1-11$.

17. Weber-Rajek M, Ciechanowska K, Mieszkowski J et al. Wpływ zasobów psychicznych na jakość życia chorych po udarze niedokrwiennym mózgu. J Health Sci. 2014; 4, 9: 51-60.

18. Paul-KańskaJ. Choroba nowotworowa-w obliczu zagrożenia życia. Folia Psychologica. 2007; 11: 37-45.

19. Rogala D, Mazur A, Maślińska $M$ et al. Poczucie własnej skuteczności i strategie przystosowania do choroby u pacjentek z nowotworem narządu rodnego. Curr Gynecol Oncol. 2015; 13, 3: 154-164.

20. Rogala D, Mazur A, Maślińska M et al. Przystosowanie do choroby nowotworowej u pacjentek z rakiem szyjki macicy. Piel Pol. 2016; 2: 170-174.

21. Szymona K. Stres związany z ciążą i czynniki wpływające na jego poziom. W: Steuden S, Ledwocha M (red.). Wybrane zagadnienia z psychologii klinicznej i osobowości. Problemy człowieka chorego. Lublin: Towarzystwo Naukowe KUL; 2005. 39-60.

22. Landowski J. Neuroendokrynologia. W: Bilikiewicz A, Pużyński S, Rybakowski J (red.). Psychiatria. Wrocław: Elsevier Urban \& Partner; 2002. 191-203.

23. Gapińska E, Tartas M, Walkiewicz M et al. Poczucie własnej skuteczności a lęk i depresja u pacjentów po zabiegu wyłonienia stomii jelitowej. Współcz Onkol. 2008; 12, 2 : 84-89.

24. Guzińska K, Kupc A, Borys B. Zasoby odporności na stres w procesie zdrowienia u pacjentów z chorobą niedokrwienną serca. Psychiatria. 2007; 4, 4: 144-152.

25. Tartas M. Poczucie własnej skuteczności a remisja w schizofrenii. Psychiatr Pol. supl.: X Gdańskie Dni Lecznictwa Psychiatrycznego. 2002; 36, 6: 249-255.

26. Wrzesińska MA, Opuchlik K, Kocur J. Ocena umiejscowienia kontroli zdrowia oraz poziomu poczucia własnej skuteczności i optymizmu u chorych na stwardnienie rozsiane. Post Psychiatr Neurol. 2008; 17, 4: 313-318.

27. Miniszewska J. Strategie radzenia sobie ze stresem a poczucie skuteczności u chorych z rozpoznaniem nowotworu narządów rodnych i wewnętrznych. Zeszyty Naukowe WSHE w Łodzi. 2002; 121: 17-23.

28. Życińska J. Znaczenie poczucia własnej skuteczności w kształtowaniu obrazu siebie i jakości związku małżeńskiego przez kobiety po mastektomii. W: Kubacka-Jasiecka D, Ostrowski TM (red.). Psychologiczny wymiar zdrowia, kryzysu i choroby. Kraków: Wyd. Uniwersytetu Jagiellońskiego; 2005. 221-239. 
29. Agrawal P, Pająk J. Poród aktywny. Ginekol Pol. 2000; 74, 1: 179-182.

30. Laudański T. Hydroterapia w perinatologii. Klin Perinatol Ginekol. 2000; supl. XXV: 84-87.

31. Laudański T. Modyfikacja środowiska narodzin - potrzeby matki i dziecka a potrzeby nowoczesnego położnictwa. Ginekol Pol. 2001; 72, 8: 668-673.

32. Wybrańczyk K. Poród w immersji wodnej. Now Lek. 2003; 6: 477-479.

33. Gupta JK, Hofmeyr GJ, Smyth RMD. Position in the second stage of labour for women without epidural anaesthesia. Cochrane Database Syst Rev. 2004; 1.

34. Cluett ER, Burns E. Immersion in water in labour and birth. Cochrane Database Syst Rev. 2009; 2.

35. Dowswell T, Bedwell C, Lavender T et al. Transcutaneous electrical nerve stimulation (TENS) for pain relief in labour. Cochrane Database Syst Rev. 2009; 2.

36. Lawrence A, Lewis L, Hofmeyr GJ et al. Maternal positions and mobility during fi rst stage labour. Cochrane Database Syst Rev. 2009; 2.

37. Gupta JK, Hofmeyr GJ, Shehmar M. Position in the second stage of labour for women without epidural anaesthesia. Cochrane Database Syst Rev. 2012; 5.

38. Zakrzewski J. Poczcie skuteczności a samoregulacja zachowania. Prz Psychol. 1987; 3: 661-678.
39. Parent N, Fortin F. A randomized, controlled trial of vicarious experience thought peer support for male first-time cardiac surgery patients: impact on anxiety, self-efficacy expectation and self-reported activity. Heart Lung. 2000; 29, 6: 389-400.

40. Noga $H$, Voytsel $N$. Orientacja pozytywna, przekonanie o własnej skuteczności a treningi neurofeedback. Edukacja - Technika - Informatyka. 2016; 2, 16: 47-55.

Artykuł przyjęty do redakcji: 20.12.2016

Artykuł przyjęty do publikacj: 16.02.2017

Źródło finansowania: Praca nie jest finansowana z żadnego źródła. Konflikt interesów: Autorzy deklarują brak konfliktu interesów.

\section{Adres do korespondencji:}

Dorota Rogala

ul. Izabeli Romanowskiej 2

85-796 Bydgoszcz

tel.: 525855814

e-mail:drogala@cm.umk.pl

Klinika Ginekologii Onkologicznej

Centrum Onkologii im. prof. Franciszka Łukaszczyka

w Bydgoszczy 